\title{
Antibody-Mediated Therapy against HIV/AIDS: Where Are We Standing Now?
}

\author{
Noel Jacques Awi and Sin-Yeang Teow \\ Department of Medical Sciences (DMS), School of Healthcare and Medical Sciences (SHMS), Sunway University, \\ Jalan Universiti, Bandar Sunway, 47500 Subang Jaya, Selangor Darul Ehsan, Malaysia
}

Correspondence should be addressed to Sin-Yeang Teow; ronaldt@sunway.edu.my

Received 25 January 2018; Revised 10 April 2018; Accepted 26 April 2018; Published 3 June 2018

Academic Editor: Nongnuch Vanittanakom

Copyright (C) 2018 Noel Jacques Awi and Sin-Yeang Teow. This is an open access article distributed under the Creative Commons Attribution License, which permits unrestricted use, distribution, and reproduction in any medium, provided the original work is properly cited.

\begin{abstract}
Acquired immunodeficiency syndrome (AIDS) cases are on the rise globally. To date, there is still no effective measure to eradicate the causative agent, human immunodeficiency virus (HIV). Highly active antiretroviral therapy (HAART) is being used in HIV/AIDS management, but it results in long-term medication and has major drawbacks such as multiple side effects, high cost, and increasing the generation rate of escape mutants. In addition, HAART does not control HIV-related complications, and hence more medications and further management are required. With this, other alternatives are urgently needed. In the past, smallmolecule inhibitors have shown potent antiviral effects, and some of them are now being evaluated in clinical trials. The challenges in developing these small molecules for clinical use include the off-target effect, poor stability, and low bioavailability. On the other hand, antibody-mediated therapy has emerged as an important therapeutic modality for anti-HIV therapeutics development. Many antiviral antibodies, namely, broad neutralizing antibodies (bnAbs) against multiple strains of HIV, have shown promising effects in vitro and in animal studies; further studies are ongoing in clinical trials to evaluate their uses in clinical applications. This short review aims to discuss the current development of therapeutic antibodies against HIV and the challenges in adopting them for clinical use.
\end{abstract}

\section{Current HIV Treatments}

The discovery of HAART in 1996 has successfully reduced the global mortality rate due to HIV/AIDS [1]. This therapeutic strategy targets multiple viral proteins that are essential for viral replication and dissemination (e.g., envelope protein, reverse transcriptase, integrase, and protease), instead of targeting a single target. This combination therapy could potently suppress the viral load to minimal level. However, the treatment cost is extremely high and this therapy often results in numerous side effects that significantly affect the patients' life quality [2]. Depending on the conditions, the mild side effects could be weight loss, diarrhoea, anaemia, constipation, dizziness, insomnia, headache, fatigue, rashes, abdominal pain, emotions, nausea, and vomiting, while the potentially fatal complications are liver failure, lipodystrophy, and neurological and cardiovascular diseases [2]. In addition to physical health, other problems in mental and social health have also been reported [2]. It has also been shown that the use of HAART leads to long-term medication of HIV/AIDS patients, and it could introduce multiple drugresistant escape mutants due to the high mutation rate and recombination frequency of the virus [3]. A large number of drug-resistant HIV variants have been previously reported, and they are known to be resistant to various drug groups such as nucleoside reverse transcriptase inhibitors (NRTIs), nonnucleoside reverse transcriptase inhibitors (NNRTIs), protease inhibitors, integrase inhibitors, and entry inhibitors [3]. Hence, other more effective and less toxic alternatives are urgently needed to treat HIV/AIDS. A proper use of anti-HIV drug is also important in order to control the overwhelming number of escape mutants.

In the past, small-molecule inhibitors have demonstrated promising antiviral effects against HIV [4-7]. These inhibitors target various viral proteins such as integrase [8], nucleocapsid [9], capsid [10], and envelope [11] as well as 
cellular proteins of target cells such as CD4 [12], kinases [13], and cellular cofactor [14]. T20 peptide (Enfuvirtide) is the first HIV entry inhibitor approved by United States Food and Drug Administration (U. S. FDA) in 2003 [15] followed by the approval of the first chemokine receptor 5 (CCR5) small-molecule antagonist, Maraviroc (Selzentry) in 2007 [16]. However, these drugs have their limitations in the clinical applications $[6,17]$. Meanwhile, other small-molecule inhibitors are being evaluated in clinical trials. For instances, small-molecule NNRTIs, cabotegravir, and rilpivirine were evaluated in randomised phase $2 \mathrm{~b}$ trials and the result of the trial has been recently published [18]. Following Maraviroc, small-molecule CCR5 antagonists, aplaviroc, and vicriviroc are currently being evaluated in phase $2 \mathrm{~b}$ clinical trials for HIV therapy [19]. A small-molecule ABX464 that inhibits $\mathrm{HIV}$ replication is also expected to enter phase $2 \mathrm{~b}$ trials in 2018 [20]. Despite the advancement of biological and chemical engineering technology, it remains a huge challenge to deliver a safe, stable, and functional molecule into the host system to completely eradicate the residing virus [6].

Antibody-based therapies possess several advantages over the chemical-based treatment in various aspects such as specificity and safety [21]. A number of therapeutic antibodies have been approved by FDA for cancer therapies [22]. In the past three years, therapeutic antibodies targeting programmed death protein $1(\mathrm{PD}-1)$ and programmed death ligand 1 (PDL1) to boost human immune responses against cancer cells [23] have been approved by FDA to treat various cancers including melanoma [24], non-small cell lung cancer (NSCLC) [25], and head and neck squamous cell carcinoma (HNSCC) [26]. For viral infection prevention and treatment, several antibodies targeting multiple types of viruses such as human cytomegalovirus (HCMV), influenza, respiratory syncytial virus (RSV), Ebola, rabies, and HIV are being evaluated in clinical trials [21]. The development of therapeutic antibodies, in particular, the broad neutralizing antibodies (bnAbs) against various HIV strains, will be emphasized and discussed in later sections.

\section{Development of HIV-1-Neutralizing Antibodies against HIV/AIDS}

Broad neutralizing antibodies (bnAbs) are neutralizing antibodies that neutralize multiple HIV-1 viral strains by targeting conserved epitopes of virus [60]. BnAbs have shown promising effects against various HIV strains and have significantly contributed to HIV vaccine development [60]. The earliest bnAb, b12 were discovered in 1991 [61], and increasing bnAbs have been seen in recent years [60]. All of the bnAbs information is freely available on a website known as broadly neutralizing antibodies electronic resource (bNAber) which aims to support the researchers to generate a potent HIV vaccine [62]. Table 1 shows a list of bnAbs targeting multiple HIV-1 epitopes in the past 10 years. These bnAbs were raised from blood of HIV-1 infected patients and this information is tabulated in Table 1. Generally, anti-HIV bnAbs can be categorized into two groups: first and second [63]. Both of these groups differ from the method used for generation of bnAbs and their functionalities. Examples of "first-generation" antibodies are b12, 2G12, 4E10, and 2F5. These bnAbs were developed from Epstein-Barr virus- (EBV) immortalized B cells and generated using phage-display methods [63]. Although these bnAbs resulted in 50\%-88\% of neutralization breadth, they are not ideal for antibodybased vaccine mainly due to the relatively low neutralization efficacy and limitation of method such as antibody specificity selection and lack of high throughput screening option [64]. On the other hand, "second-generation" bnAbs possess improved neutralization potency and offer high flexibility in technology manipulation. The advancement of technology allows the selection of chronically HIV-1-infected "Elite neutralizers," new screening and selection method, and new antibody isolation and analysis method [64]. Examples of "second-generation" bnAbs are PG9, PG16, CH01, PGT145, PGT121, PGDM1400, 10-1074, 10E8, VRC01, 3BNC117, and CH103.

To date, none of the FDA-approved therapeutic antibodies are used for HIV treatment. The development of therapeutic antibodies against HIV is ongoing and many of them have successfully progressed to human clinical trials $[46,65]$. Table 2 shows the anti-HIV antibodies that are being evaluated in different phases of trials. HIV-1 envelope protein is a popular therapeutic target for various antiviral pharmaceuticals and vaccine design [66]. Scheid and group demonstrated the result of phase $2 \mathrm{a}$ trial using HIV Env-specific antibody, 3BNC117 on $13 \mathrm{HIV}$-infected patients. They showed that the broad neutralizing antibody (bnAb) 3BNC117 exerted strong selective pressure on HIV-1 emerging from latent reservoirs [43]. Similarly, another monoclonal antibody, 101074 targeting V3 glycan site of HIV-1 Env protein, showed potent effect and high tolerant limit in phase I trial [44]. Bar and colleagues showed another bnAb, VRC01 to effectively suppress the plasma viremia below detectable concentration in phase I trial [45]. The same study also highlighted the emergence of VRC01-resistant HIV after the exposure as the main challenge [45]. Other monoclonal antibodies targeting HIV envelope glycoproteins that are currently under phase I trials are PGDM1400, PGT121, N6, and 10E8v4 (Table 2) [46]. Recently, Xu and group generated highly potent trispecific antibodies by combining the specificity of PGDM1400, VRC01, and 10E8v4 [47]. These engineered antibodies interact with three different sites of envelope protein: membraneproximal external region (MPER)-, CD4-, and V1V2-binding sites. These antibodies conferred a complete immunity by displaying high breadth and potency against simian-human immunodeficiency viruses (SHIVs) in nonhuman primates compared to each parental antibody. This antibody developed by Sanofi is expected to enter phase I trial in late 2018 [47].

Antibodies that are targeting cellular proteins essential for HIV replication such as CD4 and coreceptors have also been shown to efficaciously eradicate the HIV. Some of these antibodies are undergoing clinical trials. TMB-355 (previously known as TMB-301), also known as ibalizumab, targets CD 4 receptor and prevents the viruses from binding to them. A phase 3 trial demonstrated that ibalizumab is a safe and well-tolerated drug and can be used as a monotherapy especially for multidrug-resistant HIV patients with limited treatment options [51]. Researchers are currently developing 
TABLE 1: Anti-HIV broad neutralizing antibodies (bnAbs) in the past 10 years.

\begin{tabular}{|c|c|c|c|c|}
\hline Viral epitope & Name & Year & Sample source & References \\
\hline \multirow{4}{*}{ V1V2 glycan site } & PG9, PG16 & 2009 & Clade A-infected African & {$[27]$} \\
\hline & $\mathrm{CH} 01$ & 2011 & Chronically infected donor (CH0219) & {$[28]$} \\
\hline & PGT145 & 2011 & Chronically infected donor 84 & {$[29]$} \\
\hline & PGDM1400 & 2014 & Chronically infected donor 84 & {$[30]$} \\
\hline \multirow{2}{*}{ V3 glycan site } & PGT121, PGT125, PGT135 & 2011 & HIV-1 infected donor (at least 3 years) & [29] \\
\hline & $10-1074$ & 2011 & Clade A-infected African donor (patient 10) & [31] \\
\hline \multirow{7}{*}{ gp41 MPER } & $2 \mathrm{~F} 5$ & 2009 & PBMCs from patient SC44 & {$[32]$} \\
\hline & $4 \mathrm{E} 10$ & 2009 & PBMCs from patient SC44 & {$[32]$} \\
\hline & HK20 & 2010 & Patients plasma that showed $>80 \%$ neutralization & [33] \\
\hline & M66.6 & 2011 & PBMCs from patient SC44 & {$[32]$} \\
\hline & CAP206-CH12 & 2011 & Subtype C HIV-1-infected South African donor CAP206 & {$[34]$} \\
\hline & $10 \mathrm{E} 8$ & 2012 & HIV-1-infected patient N152 & [35] \\
\hline & $\mathrm{m} 43$ & 2012 & Phage-display & {$[36]$} \\
\hline \multirow{16}{*}{ CD4 binding site } & VRC01 & 2010 & PBMCs from donor 45 & {$[37]$} \\
\hline & HJ16 & 2010 & Patients plasma that showed $>80 \%$ neutralization & [33] \\
\hline & HGN194 & 2010 & Patients plasma that showed $>80 \%$ neutralization & {$[33]$} \\
\hline & 3BNC117 & 2011 & RU01 B-cell clones from patient donor & [38] \\
\hline & 3BNC55 & 2011 & RU01 B-cell clones from patient donor & [38] \\
\hline & VRC-PG04 & 2011 & Clade A1/D infected donor & [39] \\
\hline & VRC-CH31 & 2011 & Chronically infected donor (CH0219) & {$[28]$} \\
\hline & NIH45 & 2011 & RU12 B-cell clones from patient donor & [38] \\
\hline & 8ANC195 & 2011 & RU12 B-cell clones from patient donor & [38] \\
\hline & 8ANC131 & 2011 & HIV-1 infected donor RU8 & [38] \\
\hline & $12 \mathrm{~A} 12$ & 2011 & RU16 B-cell clones from patient donor & [38] \\
\hline & 1B2530 & 2011 & HIV-1 infected donor RU1 & [38] \\
\hline & $3 \mathrm{BC} 176$ & 2012 & HIV-1 infected patient $3 \mathrm{~B}$ & {$[40]$} \\
\hline & 3BC315 & 2012 & HIV-1 infected patient 3B & {$[40]$} \\
\hline & $\mathrm{CH} 103$ & 2013 & HIV-1 infected donor CH505 & {$[41]$} \\
\hline & N6 & 2016 & HIV-1-infected patient Z258 & {$[42]$} \\
\hline
\end{tabular}

TABLE 2: Therapeutic antibodies that are being evaluated in the clinical trials.

\begin{tabular}{|c|c|c|c|c|}
\hline Source & Target & Name & Clinical trial & References \\
\hline \multirow{7}{*}{ Viral } & Env CD4 binding site & 3BNC117 & Phase $2 \mathrm{a}$ & {$[43]$} \\
\hline & Env V3 glycan site & $10-1074$ & Phase I & {$[44]$} \\
\hline & Env CD4 binding site & VRC01 & Phase I & {$[45]$} \\
\hline & V1V2 & PGDM1400 & Phase I & [42] \\
\hline & Env V3 glycan site & PGT121 & Phase I & {$[46]$} \\
\hline & Env MPER & $10 \mathrm{E} 8 \mathrm{v} 4$ & Phase I & {$[47]$} \\
\hline & Env CD4 binding site & N6 & Phase II & {$[42]$} \\
\hline \multirow{5}{*}{ Cellular } & CCR5 & HGS004 & Phase I & {$[48]$} \\
\hline & CCR5 & PRO140 & Phase III & {$[49]$} \\
\hline & CCR5/CCR2 & Cenicriviroc & Phase III & {$[50]$} \\
\hline & CD4 & TMB-355 & Phase III & {$[51]$} \\
\hline & PDL1 & BMS-936559 & Phase I & {$[52]$} \\
\hline
\end{tabular}

a new formulation of ibalizumab for the intramuscular injection use [51]. Various antibodies targeting chemokine coreceptor 5 (CCR5), such as HGS004, PRO140, and Cenicriviroc (Table 2), have shown promising antiviral effects and are now being evaluated in clinical trials. An antiPDL1 antibody, BMS-936559 has been evaluated in a phase
I trial on HIV patients, and the results showed that the immunologic checkpoint inhibitor could enhance the HIVspecific immunity in a subset of participants in the trial [52]. Apart from the abovementioned antibodies, other antiHIV therapeutic antibodies are being evaluated and these antibodies have been discussed in several reviews [59, 67-69]. 
TABLE 3: Challenges of FDA-approved anti-HIV therapeutic antibodies development.

\begin{tabular}{|c|c|c|}
\hline Challenge & Notes & References \\
\hline \multirow{2}{*}{ Method } & Phage-display library is the most commonly used technique for therapeutic antibody generation. & [53] \\
\hline & The technique allows both genetic and chemical modification of antibody fragments. & [54] \\
\hline Cost & $\begin{array}{l}\text { The production cost of antibody is higher than the synthesis of small-molecule antivirals. The } \\
\text { generation of recombinant antibodies results in higher manufacturing cost. }\end{array}$ & [21] \\
\hline Host immunology & Individuals' immune responses towards therapeutic antibodies may be different & {$[55]$} \\
\hline Epidemiology & $\begin{array}{c}\text { Geographical distribution affects the resistance mechanism and neutralization escape of viral } \\
\text { strains }\end{array}$ & {$[56]$} \\
\hline Delivery & $\begin{array}{l}\text { Conjugation with cell-penetrating peptides improves the cellular delivery of antibodies. Smaller } \\
\text { antibody formats such as Fabs, sdAbs, and scFvs also facilitate tissue delivery }\end{array}$ & [57] \\
\hline Stability & Fc region engineering improves the half-life, stability, and the effector function of the antibody & [58] \\
\hline Resistant mutants & $\begin{array}{l}\text { Development of antibody-resistant HIV mutants has been reported in VRC01-treated patients, } \\
\text { combination therapy will minimize the occurrence of virus mutation }\end{array}$ & {$[45]$} \\
\hline Toxicity & $\begin{array}{l}\text { IL-2 and IFN- } \gamma \text { therapy that may be used as adjuvant therapy for bnAbs therapy to stimulate } \\
\text { T-cell killing and HIV-1 transcription resulted in high level of cytotoxicity }\end{array}$ & {$[59]$} \\
\hline
\end{tabular}

These investigational therapeutic antibodies are being evaluated preclinically before entering the human trials.

Compared with other chemical-based or small-molecule treatment, antibody-based treatment offers a more comprehensive targeting and neutralization, and hence a more potent anti-HIV actions. One of the key components of bnAbs is the IgG Fc region. Using humanized mouse models, Halper-Stromberg et al. demonstrated that the HIV suppression by the passively transferred antibodies was dependent on interaction of the IgG Fc with Fc receptors of immune cells [70]. Other studies have also highlighted the Fc receptor-mediated effector functions of bnAbs in HIV inhibition through antibody-dependent cell-mediated cytotoxicity (ADCC) against both free virus and virusinfected cells $[71,72]$. Fc domains of antibodies also interacted with natural killer cells and phagocytes for viral particle clearance and killing of virus-infected cells [73]. It is clear that while reactivity and affinity of bnAbs play pivotal roles in determining the antibody neutralization capacity, the Fcmediated effector mechanisms also play part in the antiviral activities.

\section{Challenges in Antibody-Based Therapies}

As discussed above, antiviral antibodies serve as a highly potential therapeutic modality against HIV. However, there are multiple challenges in the development of these antibodies. These challenges have intensively slowed down the FDA approval of the anti-HIV antibodies into the market. This section discusses the challenges in developing the antibodies into clinical use (summarized in Table 3).

The main challenge of antibody therapy against HIV is the method used for humanized antibody production. Phage-displayed library is the most popular platform used to generate therapeutic human antibodies in the past decade and many of these phage-display-generated antibodies have been approved by FDA or European Medicines Agency (EMA) [53, 74]. This technique enables the construction of antibodies in $\mathrm{Fab}$ or scFv fragments and display on filamentous phage. The antibodies are then isolated and enriched by panning against antigen of interest. Due to the relatively lower throughput, phage-display technique has been switched to cell sorting and RT-PCR for antibody isolation. Use of these methods has generated many more bnAbs known as "second-generation" bnAbs. Various sources have been used for the therapeutic antibody production against viruses, including total B cells [75], single memory B cells [21], and single plasma B cells [21]. Several reports have also shown the efficacy of isolating the antibodies from native phage libraries which possess potent neutralization activities against viruses [76]. The downside of this technique is that it cannot be used to identify new neutralizing epitopes of virus [21]. This method has also been described as a time-consuming and laborious approach [77]. Other alternatives to generate the therapeutic antibodies include proteomics-directed cloning of antibodies [78] and deep sequencing of paired antibodies encoding genes [79].

The development of antibody generation technique is also highly associated with the production cost. The advancement of technologies allows the production of recombinant antibodies with improved therapeutic effects as well as other refined properties including tissue delivery and stability. For instance, antibody in single-domain antibodies (sdAbs) format allows an efficient target binding and rapid tissue penetration compared to the conventional full-length antibodies; this may enhance the antiviral activities [80]. However, this strategy needs to be reconsidered as cumulative evidences have shown the importance of Fc region of Abs in antiviral action; antibodies without Fc region would significantly reduce the overall neutralizing activities [70-72]. To improve the stability and biodistribution of therapeutic full-length antibodies and the effector functions, Fc region engineering plays an important role in improving the antibody clinical efficacy [81, 82]. Antibody-based therapies are generally welltolerated and safe; however, this can be further improved by antibody engineering as previously described [83]. While antibody engineering is speculated to benefit the future of HIV/AIDS therapy, these modifications will increase the production cost compared to the standardized manufacturing 
protocol as well as the synthesis of antiviral small molecules. The production cost is the key factor for anti-HIV antibody therapy due to the smaller market in viral diseases compared to cancer diseases [21]. There is also a rising concern following the increasing number of FDA-approved small-molecule inhibitors for HIV/AIDS therapy [10, 13, 18, 20]. Although the antibody- and molecule-based therapeutics have different antiviral mechanisms, the comparison and competition between the antiviral antibodies and the substantial number of small-molecule inhibitors in the market is unavoidable.

Another challenge of developing therapeutic antibodies is the biological variation from host to host. Certain population of HIV-infected patients may not respond to a particular antibody or is suitable even though it has been proven efficacious and safe in a group of patients who have differences in terms of individuals' immunology, vaccination, diet, lifestyle, and geographical factors [21]. The treatment failure is also highly related to the biology of target virus including the mechanism of infection, mutation rate, and neutralization escape [84]. Other key challenges are the delivery and stability of antibodies for HIV therapies (Table 2). As tabulated in Table 1, all of the drug targets are viral and cellular proteins or receptors. Recent reports have highlighted the potential of targeting intracellular proteins using therapeutic antibodies for the development of HIV/AIDS therapies [85, 86]. However, conventional antibodies do not penetrate into the cells and target intracellular proteins [87]. To solve this problem, conventional antibodies can be conjugated with cell penetrating peptides (CPPs) derived from various sources to enter the cell cytoplasm [88]. Antibodies in smaller format such as Fabs, scFvs, and sdAbs (with Fc removal) have also been constructed for this purpose [57, 89, 90]. These antibodies have targeted various intracellular proteins including capsid [91], integrase [92], and other accessory proteins such as Nef [93], Vif [94], Tat [95], and Rev [96]. The clinical application of these intracellular-targeting antibodies remains to be seen.

Compared to other therapeutic modalities such as HAART and other small-molecule inhibitors, antiviral bnAbs are active against multiple types of HIV strains at low doses with acceptable toxicities [97]. For example, 3BNC117 could prevent mucosal transmission in high-dose challenge in humanized mouse models at low doses [98]. On the other hand, combination of NIH45-46m2, 10-1074, and $10 \mathrm{E} 8$ resulted in $100 \%$ neutralization of HIV-1 variants at a low concentration $\left(\mathrm{IC}_{50}\right.$ of $\leq 0.37 \mu \mathrm{g} / \mathrm{mL}$ ) compared to the individual bnAb alone [99]. Although the toxicity of antiHIV bnAbs therapy is less reported, it has been reported in other adjuvant therapies that may be used to complement the antibody therapy such as IL- 2 and IFN- $\gamma$ cytokine therapy [59].

Last but not least, the rapid viral resistance developed from the bnAbs treatment is striking and has drawn considerable attention. This is mainly due to the high mutation rate of HIV-1. The resistance has been reported in various bnAbs targeting multiple sites including V1/V2, V3, and $\mathrm{CD} 4$ binding site. Bouvin-Phey et al. reported that HIV-1 clade $\mathrm{B}$ has increased resistance towards the bnAbs targeting gp120 as shown by VRC01, NIH45-46, PG9, PG16, PGT121, and PGT128 [99]. Interestingly, the same study has also shown that no increase of viral resistance was seen in bnAbs targeting MPER of gp41 such as 2F5 and 4E10 [99]. This could be due to the lack of selective pressure and/or a weak tolerance to mutations in this particular region [99]. Similarly, the viral resistance of bnAbs has also been predicted using several computational and mathematical models [100, 101]. To circumvent this issue, multispecific bnAbs and combination of bnAbs have been developed to concurrently target various epitopes of a protein to reduce the chances of viral resistance. This includes the recent development of a trispecific bnAbs targeting two CD4-binding sites and MPER [102], and a combination of two to four bnAbs targeting CD4binding site, V1V2, V3, and MPER [103].

\section{Future Perspectives and Conclusions}

The abovementioned challenges must be looked into before the therapeutic antibodies are deemed suitable for clinical use. Development of technology and bioengineering such as advancement of antibody generation and isolation methods, improvement of target delivery, and specificity play important roles in improving the antiviral activities of therapeutic antibodies. Based on current literature, many studies demonstrated that antibody-mediated antiviral treatments have yet achieved complete inhibition against HIV-1. This may suggest that treatment using therapeutic antibodies may not be suitable to be used as a "standalone" therapy although extensive efforts are ongoing. This therapeutic modality may pose a higher value when used in combination with current anti-HIV therapies such as HAART or other antiviral smallmolecule inhibitors. For example, it has been shown that the bnAb 3BNC117 when used in combination with HAART could enhance the host immune response against HIV-1 and leads to significant delay of viral rebound after treatment cessation $[63,104]$. Although the combination treatment of small-molecule inhibitors and antiviral antibodies has not been studied, it is speculated that it will drastically improve the neutralizing potency of the HIV-1. This speculation, however, requires further investigations for validation. In addition to maximizing the neutralization efficacy, combination treatment targeting multiple sites of protein is also anticipated to significantly avert the selection of escape variants [97].

The discovery of bnAbs has also posed a significant impact on the development of anti-HIV vaccine. While bnAbs are able to tackle the extremely high diversity of HIV1 , it is understood that having a safe vaccine eliciting bnAbs could be an effective measure to control HIV spreading. However, there are no vaccination strategies by far to elicit the effective bnAbs responses [105]. Several attempts have been made to develop the vaccination strategy mainly using animal models. In both macaque and rabbit models, sequential vaccination with gp120 and gp140 proteins has shown improved potency of neutralization, respectively [106, 107]. Similarly, sequential vaccination with three gp120 variants also demonstrated potent neutralization [108]. To date, it remains unknown to elicit the bnAbs from the HIV patients through vaccination. The main challenges are the HIV-1 
diversity and later on rapid viral resistance. Sequential vaccination with various immunogens with conserved regions may promote the B cell maturation and antibody responses.

Therapeutic antibodies are known as "magic bullets" due to the fact that they can treat various diseases and infections. A number of FDA-approved therapeutic antibodies in the current market highlight the potential of adopting antibodies for disease control. Broad neutralizing antibodies have demonstrated potent antiviral action against various strains of HIV-1 and a large number of them are currently being evaluated in the clinical trials. Continuous efforts are in progress to elucidate their potential use for anti-HIV treatment in clinics. Overcoming the abovementioned challenges will undoubtedly improve the application of therapeutic antibody to HIV/AIDS management in the future.

\section{Conflicts of Interest}

The authors declare that they have no conflicts of interest.

\section{Authors' Contributions}

All authors participated in the literature search, interpretation of the articles reviewed, analysis of the data, and review of the manuscript. All authors have read and approved the paper.

\section{Acknowledgments}

The authors would like to acknowledge Sunway University Sunway Internal Research Grant 2018 (INT-2018-SHMSSIHD-01) and National Cancer Council Malaysia (MAKNA) Cancer Research Award (CRA) 2016 (EXT-SIDS-SIHDMAKNA-2017-01) for partly supporting this work. Noel Jacques Awi is a recipient of Sunway University Master's Degree by Research Scholarship.

\section{References}

[1] A. Mocroft, S. Vella, T. L. Benfield et al., "Changing patterns of mortality across Europe in patients infected with HIV-1," The Lancet, vol. 352, no. 9142, pp. 1725-1730, 1998.

[2] O. O. Oguntibeju, "Quality of life of people living with HIV and AIDS and antiretroviral therapy," HIV/AIDS-Research and Palliative Care, vol. 4, pp. 117-124, 2012.

[3] P. Iyidogan and K. S. Anderson, "Current perspectives on HIV-1 antiretroviral drug resistance," Viruses, vol. 6, no. 10, pp. 40954139, 2014.

[4] B. Debnath, S. Xu, F. Grande, A. Garofalo, and N. Neamati, "Small molecule inhibitors of CXCR4," Theranostics, vol. 3, no. 1, pp. 47-75, 2013.

[5] T. E. Smithgall and G. Thomas, "Small molecule inhibitors of the HIV-1 virulence factor, Nef," Drug Discovery Today: Technologies, vol. 10, no. 4, pp. e451-e548, 2013.

[6] L. Lu, F. Yu, L. Cai, A. K. Debnath, and S. Jiang, "Development of small-molecule HIV entry inhibitors specifically targeting gp120 or gp41," Current Topics in Medicinal Chemistry, vol. 16, no. 10, pp. 1074-1090, 2016.
[7] J. J. Tan, C. Liu, X. H. Sun et al., "Perspectives on developing small molecule inhibitors targeting HIV-1 integrase," MiniReviews in Medicinal Chemistry, vol. 12, no. 9, pp. 875-889, 2012.

[8] C. Tintori, J. Demeulemeester, L. Franchi et al., "Discovery of small molecule HIV-1 integrase dimerization inhibitors," Bioorganic \& Medicinal Chemistry Letters, vol. 22, no. 9, pp. 3109-3114, 2012.

[9] D. M. Warui and A. M. Baranger, "Identification of small molecule inhibitors of the HIV-1 Nucleocapsid-Stem-Loop 3 RNA Complex," Journal of Medicinal Chemistry, vol. 55, no. 9, pp. 4132-4141, 2012.

[10] J. P. Xu, J. D. Branson, R. Lawrence, and S. Cocklin, "Identification of a small molecule HIV-1 inhibitor that targets the capsid hexamer," Bioorganic \& medicinal chemistry letters, vol. 26, no. 3, pp. 824-828, 2016.

[11] A. Heredia, O. S. Latinovic, F. Barbault, and E. P. H. De Leeuw, "Anovel small-molecule inhibitor of hiv-1 entry," Drug Design, Development and Therapy, vol. 9, pp. 5469-5478, 2015.

[12] Q.-E. Yang, A. G. Stephen, J. W. Adelsberger et al., "Discovery of small-molecule human immunodeficiency virus type 1 entry inhibitors that target the gp120-binding domain of CD4," Journal of Virology, vol. 79, no. 10, pp. 6122-6133, 2005.

[13] F. Yi, J. Guo, D. Dabbagh et al., "Discovery of Novel SmallMolecule Inhibitors of LIM Domain Kinase for Inhibiting HIV1," Journal of Virology, vol. 91, no. 13, p. e02418-16, 2017.

[14] F. Christ, A. Voet, A. Marchand et al., "Rational design of smallmolecule inhibitors of the LEDGF/p75-integrase interaction and HIV replication," Drugs of Today (Barcelona), vol. 40, no. 3, pp. 259-269, 2004.

[15] J. P. Lalezari, K. Henry, M. O’Hearn et al., "Enfuvirtide, an HIV1 fusion inhibitor, for drug-resistant HIV infection in North and South America," The New England Journal of Medicine, vol. 348, no. 22, pp. 2175-2185, 2003.

[16] S. Sayana and H. Khanlou, "Maraviroc: A new CCR5 antagonist," Expert Review of Anti-infective Therapy, vol. 7, no. 1, pp. 9-19, 2009.

[17] B. L. Gilliam, D. J. Riedel, and R. R. Redfield, "Clinical use of CCR5 inhibitors in HIV and beyond," Journal of Translational Medicine, vol. 9, no. 1, article S9, 2011.

[18] D. A. Margolis, J. Gonzalez-Garcia, H.-J. Stellbrink et al., "Longacting intramuscular cabotegravir and rilpivirine in adults with HIV-1 infection (LATTE-2): 96-week results of a randomised, open-label, phase 2b, non-inferiority trial," The Lancet, vol. 390, no. 10101, pp. 1499-1510, 2017.

[19] E. Van Der Ryst, "Maraviroc - a CCR5 antagonist for the treatment of HIV-1 infection," Frontiers in Immunology, vol. 6, article no. 277, 2015.

[20] J.-M. Steens, D. Scherrer, P. Gineste et al., "Safety, pharmacokinetics, and antiviral activity of a novel HIV antiviral, ABX464, in treatment-naive HIV-infected subjects in a phase 2 randomized, controlled study," Antimicrobial Agents and Chemotherapy, vol. 61, no. 7, Article ID e00545-17, 2017.

[21] G. Salazar, N. Zhang, T. Fu, and Z. An, "Antibody therapies for the prevention and treatment of viral infections," NPJ Vaccines, vol. 2 , no. 1, 2017.

[22] A. M. Scott, J. D. Wolchok, and L. J. Old, "Antibody therapy of cancer," Nature Reviews Cancer, vol. 12, no. 4, pp. 278-287, 2012.

[23] H. O. Alsaab, S. Sau, R. Alzhrani et al., "PD-1 and PD-L1 checkpoint signaling inhibition for cancer immunotherapy: mechanism, combinations, and clinical outcome," Frontiers in Pharmacology, vol. 8, article no. 561, 2017. 
[24] M. K. Chuk, J. T. Chang, M. R. Theoret et al., "FDA Approval summary: accelerated approval of pembrolizumab for second-line treatment of metastatic melanoma," Clinical Cancer Research, vol. 23, no. 19, pp. 5666-5670, 2017.

[25] N. Seetharamu, I. R. Preeshagul, and K. M. Sullivan, "New PD-L1 inhibitors in non-small cell lung cancer - Impact of atezolizumab," Lung Cancer: Targets and Therapy, vol. 8, pp. 6778, 2017.

[26] X. Ran and K. Yang, "Inhibitors of the PD-1/PD-L1 axis for the treatment of head and neck cancer: Current status and future perspectives," Drug Design, Development and Therapy, vol. 11, pp. 2007-2014, 2017.

[27] D. R. Burton, L. M. Walker, S. K. Phogat et al., "Broad and potent neutralizing antibodies from an african donor reveal a new HIV-1 vaccine target," Science, vol. 326, no. 5950, pp. 285289,2009

[28] M. Bonsignori, D. C. Montefiori, X. Wu et al., "Two distinct broadly neutralizing antibody specificities of different clonal lineages in a single HIV-1-infected donor: Implications for vaccine design," Journal of Virology, vol. 86, no. 8, pp. 46884692, 2012.

[29] L. M. Walker, M. Huber, K. J. Doores et al., "Broad neutralization coverage of HIV by multiple highly potent antibodies," Nature, vol. 477, no. 7365, pp. 466-470, 2011.

[30] D. Sok, M. J. van Gils, M. Pauthner et al., "Recombinant HIV envelope trimer selects for quaternary-dependent antibodies targeting the trimer apex," Proceedings of the National Academy of Sciences of the United States of America, vol. 111, no. 49, pp. 17624-17629, 2014.

[31] H. Mouquet, L. Scharf, Z. Euler et al., "Complex-type N-glycan recognition by potent broadly neutralizing HIV antibodies," Proceedings of the National Acadamy of Sciences of the United States of America, vol. 109, no. 47, pp. E3268-E3277, 2012.

[32] X. Shen, R. J. Parks, D. C. Montefiori et al., "In vivo gp41 antibodies targeting the 2F5 monoclonal antibody epitope mediate human immunodeficiency virus type 1 neutralization breadth," Journal of Virology, vol. 83, no. 8, pp. 3617-3625, 2009.

[33] D. Corti, J. P. M. Langedijk, A. Hinz et al., "Analysis of memory $\mathrm{B}$ cell responses and isolation of novel monoclonal antibodies with neutralizing breadth from HIV-1-infected individuals," PLoS ONE, vol. 5, no. 1, Article ID e8805, 2010.

[34] L. Morris, X. Chen, M. Alam et al., "Isolation of a human antiHIV gp41 membrane proximal region neutralizing antibody by antigen-specific single B cell sorting," PLoS ONE, vol. 6, no. 9, Article ID e23532, 2011.

[35] J. Huang, G. Ofek, L. Laub et al., "Broad and potent neutralization of HIV-1 by a gp41-specific human antibody," Nature, vol. 491, no. 7424, pp. 406-412, 2012.

[36] M.-Y. Zhang, T. Yuan, J. Li et al., "Identification and characterization of a broadly cross-reactive HIV-1 human monoclonal antibody that binds to both gp120 and gp41," PLOS ONE, vol. 7, no. 9, Article ID e44241, 2012.

[37] X. Wu, Z. Y. Yang, Y. Li et al., "Rational design of envelope identifies broadly neutralizing human monoclonal antibodies to HIV-1," Science, vol. 329, no. 5993, pp. 856-861, 2010.

[38] J. F. Scheid, H. Mouquet, B. Ueberheide et al., "Sequence and structural convergence of broad and potent HIV antibodies that mimic CD4 binding," Science, vol. 333, no. 6049, pp. 1633-1637, 2011.

[39] F. Benjelloun, P. Lawrence, B. Verrier, C. Genin, and S. Paul, "Role of human immunodeficiency virus type 1 envelope structure in the induction of broadly neutralizing antibodies," Journal of Virology, vol. 86, no. 24, pp. 13152-13163, 2012.

[40] F. Klein, C. Gaebler, H. Mouquet et al., "Broad neutralization by a combination of antibodies recognizing the CD4 binding site and a new conformational epitope on the HIV-1 envelope protein," The Journal of Experimental Medicine, vol. 209, no. 8, pp. 1469-1479, 2012.

[41] H. X. Liao, R. Lynch, and T. Zhou, "Co-evolution of a broadly neutralizing HIV-1 antibody and founder virus," Nature, vol. 496, no. 7446, pp. 469-476, 2013.

[42] J. Huang, B. H. Kang, E. Ishida et al., "Identification of a CD4-binding-site antibody to HIV that evolved near-pan neutralization breadth," Immunity, vol. 45, no. 5, pp. 1108-1121, 2016.

[43] J. F. Scheid, J. A. Horwitz, Y. Bar-On et al., "HIV-1 antibody 3BNC117 suppresses viral rebound in humans during treatment interruption," Nature, vol. 535, no. 7613, pp. 556-560, 2016.

[44] M. Caskey, T. Schoofs, H. Gruell et al., "Antibody 10-1074 suppresses viremia in HIV-1-infected individuals," Nature Medicine, vol. 23, no. 2, pp. 185-191, 2017.

[45] K. J. Bar, M. C. Sneller, L. J. Harrison et al., "Effect of HIV antibody VRC01 on viral rebound after treatment interruption," The New England Journal of Medicine, vol. 375, no. 21, pp. 20372050, 2016.

[46] K. E. Stephenson and D. H. Barouch, "Broadly Neutralizing Antibodies for HIV Eradication," Current HIV/AIDS Reports, vol. 13, no. 1, pp. 31-37, 2016.

[47] L. Xu, A. Pegu, E. Rao et al., "Trispecific broadly neutralizing HIV antibodies mediate potent SHIV protection in macaques," Science, vol. 358, no. 6359, pp. 85-90, 2017.

[48] W. C. Olson and J. M. Jacobson, "CCR5 monoclonal antibodies for HIV-1 therapy," Current Opinion in HIV and AIDS, vol. 4, no. 2, pp. 104-111, 2009.

[49] CytoDyn, Inc, "A Phase 2b/3, multicenter study to assess the treatment strategy of using PRO 140 SC as long-acting single-agent maintenance therapy for 48 weeks in virologically suppressed subjects with CCR5-tropic HIV-1 infection", In: ClinicalTrials.gov. Bethesda (MD): National Library of Medicine (US). Registered on July 13, 2016. NLM Identifier: NCT02859961.

[50] S. L. Friedman, V. Ratziu, S. A. Harrison et al., "A randomized, placebo-controlled trial of cenicriviroc for treatment of nonalcoholic steatohepatitis with fibrosis," Hepatology, vol. 67, no. 5, pp. 1754-1767, 2018.

[51] S. A. Iacob and D. G. Iacob, "Ibalizumab Targeting CD4 Receptors, An Emerging Molecule in HIV Therapy," Frontiers in Microbiology, vol. 8, article no. 2323, 2017.

[52] C. L. Gay, R. J. Bosch, J. Ritz et al., "Clinical Trial of the AntiPD-L1 Antibody BMS-936559 in HIV-1 Infected Participants on Suppressive Antiretroviral Therapy," The Journal of Infectious Diseases, vol. 215, no. 11, pp. 1725-1733, 2017.

[53] A. Frenzel, T. Schirrmann, and M. Hust, "Phage display-derived human antibodies in clinical development and therapy," $m A b s$, vol. 8, no. 7, pp. 1177-1194, 2016.

[54] K. Hodyra and K. Dąbrowska, "Molecular and Chemical Engineering of Bacteriophages for Potential Medical Applications," Archivum Immunologiae et Therapia Experimentalis, vol. 63, no. 2, pp. 117-127, 2015.

[55] A. Saez-Cirion, B. Jacquelin, F. Barré-Sinoussi, and M. MüllerTrutwin, "Immune responses during spontaneous control of HIV and AIDS: what is the hope for a cure?" Philosophical 
Transactions of the Royal Society B: Biological Sciences, vol. 369, no. 1645, p. 20130436, 2014.

[56] M. Bouvin-Pley, M. Morgand, A. Moreau et al., "Evidence for a Continuous Drift of the HIV-1 Species towards Higher Resistance to Neutralizing Antibodies over the Course of the Epidemic," PLoS Pathogens, vol. 9, no. 7, Article ID e1003477, 2013.

[57] S. Y. Teow, Cell-penetrating antibodies for targeting HIV-1 p24 capsid protein [Ph.D. thesis], Universiti Sains Malaysia, Penang, Malaysia, Chapter 4, pp. 281-329, 2015.

[58] A. W. Boesch, G. Alter, and M. E. Ackerman, "Prospects for engineering HIV-specific antibodies for enhanced effector function and half-life," Current Opinion in HIV and AIDS, vol. 10, no. 3, pp. 160-169, 2015.

[59] A. Halper-Stromberg and M. C. Nussenzweig, "Towards HIV-1 remission: Potential roles for broadly neutralizing antibodies," The Journal of Clinical Investigation, vol. 126, no. 2, pp. 415-423, 2016.

[60] D. R. Burton and L. Hangartner, "Broadly Neutralizing Antibodies to HIV and Their Role in Vaccine Design," Annual Review of Immunology, vol. 34, pp. 635-659, 2016.

[61] D. R. Burton, C. F. Barbas III, M. A. A. Persson, S. Koenig, R. M. Changcr, and R. A. Lerner, "A large array of human monoclonal antibodies to type 1 human immunodeficiency virus from combinatorial libraries of asymptomatic seropositive individuals," Proceedings of the National Acadamy of Sciences of the United States of America, vol. 88, no. 22, pp. 10134-10137, 1991.

[62] A. M. Eroshkin, A. Leblanc, D. Weekes et al., "BNAber: Database of broadly neutralizing HIV antibodies," Nucleic Acids Research, vol. 42, no. 1, pp. D1133-D1139, 2014.

[63] Z. Zhang, Q. Guan, and H. Yuan, "HIV-1 Broadly Neutralizing Antibodies: Identification, Development and Vaccine Evaluation," Journal of AIDS \& Clinical Research, vol. 7, article 636, 2016.

[64] D. N. Shcherbakov, A. Y. Bakulina, L. I. Karpenko, and A. A. Ilyichev, "Broadly neutralizing antibodies against HIV-1 as a novel aspect of the immune response," Acta Naturae, vol. 7, no. 4, pp. 11-21, 2015.

[65] D. M. Margolis, R. A. Koup, and G. Ferrari, "HIV antibodies for treatment of HIV infection," Immunological Reviews, vol. 275, no. 1, pp. 313-323, 2017.

[66] C. Cicala, F. Nawaz, K. Jelicic, J. Arthos, and A. S. Fauci, "Hiv1 gp120: A target for therapeutics and vaccine design," Current Drug Targets, vol. 17, no. 1, pp. 122-135, 2016.

[67] G. Ferrari, B. F. Haynes, S. Koenig, J. L. Nordstrom, D. M. Margolis, and G. D. Tomaras, "Envelope-specific antibodies and antibody-derived molecules for treating and curing HIV infection," Nature Reviews Drug Discovery, vol. 15, no. 12, pp. 823-834, 2016.

[68] A. P. West, L. Scharf, J. F. Scheid, F. Klein, P. J. Bjorkman, and M. C. Nussenzweig, "Structural insights on the role of antibodies in HIV-1 vaccine and therapy," Cell, vol. 156, no. 4, pp. 633-648, 2014.

[69] C. A. Derdeyn, P. L. Moore, and L. Morris, "Development of broadly neutralizing antibodies from autologous neutralizing antibody responses in HIV infection," Current Opinion in HIV and AIDS, vol. 9, no. 3, pp. 210-216, 2014.

[70] A. Halper-Stromberg, C.-L. Lu, F. Klein et al., "Broadly neutralizing antibodies and viral inducers decrease rebound from HIV1 latent reservoirs in humanized mice," Cell, vol. 158, no. 5, pp. 989-999, 2014.
[71] S. Bournazos, F. Klein, J. Pietzsch, M. S. Seaman, M. C. Nussenzweig, and J. V. Ravetch, "Broadly neutralizing antiHIV-1 antibodies require Fc effector functions for in vivo activity.," Cell, vol. 158, no. 6, pp. 1243-1253, 2014.

[72] B. von Bredow, J. F. Arias, L. N. Heyer et al., "Comparison of antibody-dependent cell-mediated cytotoxicity and virus neutralization by HIV-1 Env-specific monoclonal antibodies," Journal of Virology, vol. 90, no. 13, pp. 6127-6139, 2016.

[73] C. L. Lu, D. K. Murakowski, S. Bournazoz et al., "Enhanced clearance of HIV-1-infected cells by broadly neutralizing antibodies against HIV-1 in vivo," Science, vol. 352, no. 6288, pp. 1001-1004, 2016.

[74] H. Shim, “Therapeutic antibodies by phage display," Current Pharmaceutical Design, vol. 22, no. 43, pp. 6538-6559, 2016.

[75] P. W. Hammond, "Accessing the human repertoire for broadly neutralizing HIV antibodies," $m A b s$, vol. 2, no. 2, pp. 157-164, 2010.

[76] T. Unkauf, S. Miethe, V. Fühner, T. Schirrmann, A. Frenzel, and M. Hust, "Generation of recombinant antibodies against toxins and viruses by phage display for diagnostics and therapy," Advances in Experimental Medicine and Biology, vol. 917, pp. 5576, 2016.

[77] D. Ponsel, J. Neugebauer, K. Ladetzki-Baehs, and K. Tissot, "High affinity, developability and functional size: The holy grail of combinatorial antibody library generation," Molecules, vol. 16, no. 5, pp. 3675-3700, 2011.

[78] S. Sato, S. A. Beausoleil, L. Popova et al., "Proteomics-directed cloning of circulating antiviral human monoclonal antibodies," Nature Biotechnology, vol. 30, no. 11, pp. 1039-1043, 2012.

[79] B. J. Dekosky, G. C. Ippolito, R. P. Deschner et al., "Highthroughput sequencing of the paired human immunoglobulin heavy and light chain repertoire," Nature Biotechnology, vol. 31, no. 2, pp. 166-169, 2013.

[80] Y. Wu, S. Jiang, and T. Ying, "Single-domain antibodies as therapeutics against human viral diseases," Frontiers in Immunology, vol. 8, article no. 1802, 2017.

[81] S. Bournazos and J. V. Ravetch, "Anti-retroviral antibody Fc $\gamma$ Rmediated effector functions," Immunological Reviews, vol. 275, no. 1, pp. 285-295, 2017.

[82] F. Nimmerjahn, "A constant threat for HIV: Fc-engineering to enhance broadly neutralizing antibody activity for immunotherapy of the acquired immunodeficiency syndrome," European Journal of Immunology, vol. 45, no. 8, pp. 2183-2190, 2015.

[83] X. Wang, M. Mathieu, and R. J. Brezski, "IgG Fc engineering to modulate antibody effector functions," Protein \& Cell, pp. 1-11, 2017.

[84] M. Huber, W. C. Olson, and A. Trkola, "Antibodies for HIV treatment and prevention: Window of opportunity?" Current Topics in Microbiology and Immunology, vol. 317, pp. 39-66, 2008.

[85] L. Bao, C. Hannon, A. Cruz-Mignoni et al., "Intracellular immunization against HIV infection with an intracellular antibody that mimics HIV integrase binding to the cellular LEDGF protein," Scientific Reports, vol. 7, no. 1, Article ID 16869, 2017.

[86] K. Chupradit, S. Moonmuang, S. Nangola et al., "Current peptide and protein candidates challenging HIV therapy beyond the vaccine Era," Viruses, vol. 9, no. 10, article no. 281, 2017.

[87] A. L. J. Marschall and S. Dübel, "Antibodies inside of a cell can change its outside: Can intrabodies provide a new therapeutic paradigm?" Computational and Structural Biotechnology Journal, vol. 14, pp. 304-308, 2016. 
[88] A. Dinca, W.-M. Chien, and M. T. Chin, "Intracellular delivery of proteins with cell-penetrating peptides for therapeutic uses in human disease," International Journal of Molecular Sciences, vol. 17, no. 2, article no. 263, 2016.

[89] S. Muller, Y. Zhao, T. L. Brown, A. C. Morgan, and H. Kohler, "TransMabs: Cell-penetrating antibodies, the next generation," Expert Opinion on Biological Therapy, vol. 5, no. 2, pp. 237-241, 2005.

[90] M. A. C. Nordin and S. Teow, "Review of Current CellPenetrating Antibody Developments for HIV-1 Therapy," Molecules, vol. 23, no. 2, p. 335, 2018.

[91] S. A. Ali, S.-Y. Teow, T. C. Omar, A. S.-B. Khoo, T. S. Choon, and N. M. Yusoff, "A cell internalizing antibody targeting capsid protein (p24) inhibits the replication of HIV-1 in T cells lines and PBMCS: A proof of concept study," PLoS ONE, vol. 11, no. 1, Article ID e0145986, 2016.

[92] M. BouHamdan, J. Kulkosky, L.-X. Duan, and R. J. Pomerantz, "Inhibition of HIV-1 replication and infectivity by expression of a fusion protein, VPR-anti-integrase single-chain variable fragment (SFv): Intravirion molecular therapies," Journal of Human Virology, vol. 3, no. 1, pp. 6-15, 2000.

[93] J. Bouchet, S. E. Basmaciogullari, P. Chrobak et al., "Inhibition of the Nef regulatory protein of HIV-1 by a single-domain antibody," Blood, vol. 117, no. 13, pp. 3559-3568, 2011.

[94] J. Goncalves, F. Silva, A. Freitas-Vieira et al., "Functional neutralization of HIV-1 Vif protein by intracellular immunization inhibits reverse transcription and viral replication," The Journal of Biological Chemistry, vol. 277, no. 35, pp. 32036-32045, 2002.

[95] A. M. Mhashilkar, J. LaVecchio, B. Eberhardt et al., "Inhibition of human immunodeficiency virus type 1 replication in vitro in acutely and persistently infected human CD4+ mononuclear cells expressing murine and humanized anti-human immunodeficiency virus type 1 Tat single- chain variable fragment intrabodies," Human Gene Therapy, vol. 10, no. 9, pp. 1453-1467, 1999.

[96] X. Zhuang, S. J. Stahl, N. R. Watts, M. A. DiMattia, A. C. Steven, and P. T. Wingfield, "A cell-penetrating antibody fragment against HIV-1 Rev has high antiviral activity: Characterization of the paratope," The Journal of Biological Chemistry, vol. 289, no. 29, pp. 20222-20233, 2014.

[97] M. Caskey, F. Klein, and M. C. Nussenzweig, "Broadly neutralizing antibodies for HIV-1 prevention or immunotherapy," The New England Journal of Medicine, vol. 375, no. 21, pp. 2019-2021, 2016.

[98] M. Caskey, F. Klein, J. C. Lorenzi et al., "Viraemia suppressed in HIV-1-infected humans by broadly neutralizing antibody 3BNC117," Nature, vol. 522, no. 7557, pp. 487-491, 2015.

[99] M. Bouvin-Pley, M. Morgand, L. Meyer et al., "Drift of the HIV1 envelope glycoprotein gp120 toward increased neutralization resistance over the course of the epidemic: A comprehensive study using the most potent and broadly neutralizing monoclonal antibodies," Journal of Virology, vol. 88, no. 23, pp. 1391013917, 2014.

[100] A. Hake and N. Pfeifer, "Prediction of HIV-1 sensitivity to broadly neutralizing antibodies shows a trend towards resistance over time," PLoS Computational Biology, vol. 13, no. 10, Article ID e1005789, 2017.

[101] K. Wagh, T. Bhattacharya, C. Williamson et al., "Optimal Combinations of Broadly Neutralizing Antibodies for Prevention and Treatment of HIV-1 Clade C Infection," PLoS Pathogens, vol. 12, no. 3, Article ID e1005520, 2016.
[102] J. J. Steinhardt, J. Guenaga, H. L. Turner et al., "Rational design of a trispecific antibody targeting the HIV-1 Env with elevated anti-viral activity," Nature Communications, vol. 9, no. 1, 2018.

[103] R. Kong, M. K. Louder, K. Wagh et al., "Improving neutralization potency and breadth by combining broadly reactive HIV-1 antibodies targeting major neutralization epitopes," Journal of Virology, vol. 89, no. 5, pp. 2659-2671, 2015.

[104] T. Schoofs, F. Klein, M. Braunschweig et al., "HIV-1 therapy with monoclonal antibody 3BNC117 elicits host immune responses against HIV-1," Science, vol. 352, no. 6288, pp. 997-1001, 2016.

[105] Y. Ahmed, M. Tian, and Y. Gao, "Development of an antiHIV vaccine eliciting broadly neutralizing antibodies," AIDS Research and Therapy, vol. 14, no. 1, article no. 50, 2017.

[106] A. Mörner, I. Douagi, M. N. E. Forsell et al., "Human immunodeficiency virus type 1 Env trimer immunization of macaques and impact of priming with viral vector or stabilized core protein," Journal of Virology, vol. 83, no. 2, pp. 540-551, 2009.

[107] D. C. Malherbe, N. A. Doria-Rose, L. Misher et al., "Sequential immunization with a subtype B HIV-1 envelope quasispecies partially mimics the in Vivo development of neutralizing antibodies," Journal of Virology, vol. 85, no. 11, pp. 5262-5274, 2011.

[108] S. Wang, J. Mata-Fink, B. Kriegsman et al., "Manipulating the selection forces during affinity maturation to generate crossreactive HIV antibodies," Cell, vol. 160, no. 4, pp. 785-797, 2015. 


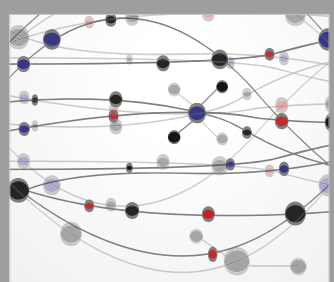

The Scientific World Journal
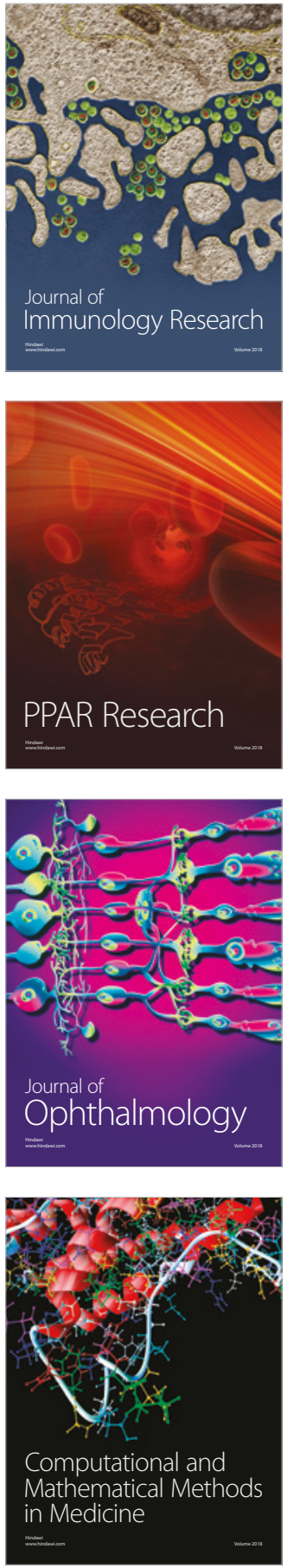

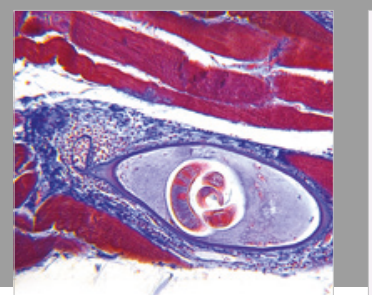

Gastroenterology Research and Practice

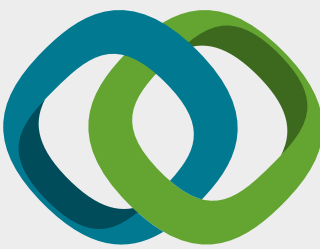

\section{Hindawi}

Submit your manuscripts at

www.hindawi.com
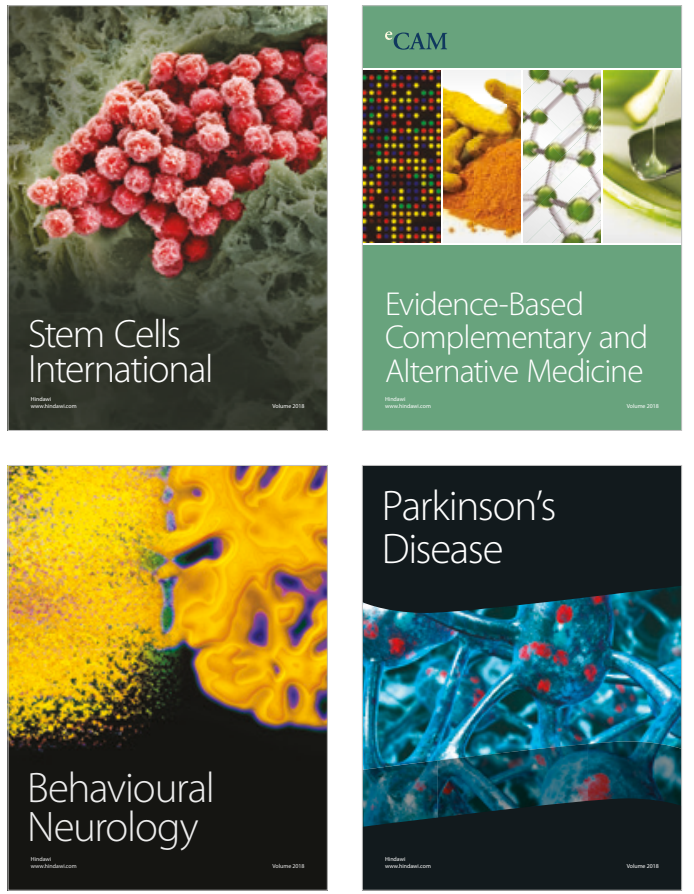

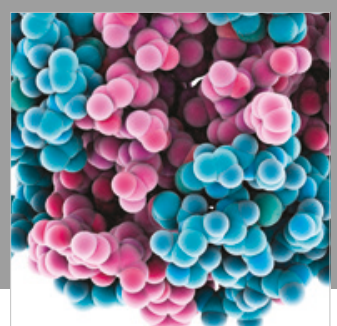

ournal of

Diabetes Research

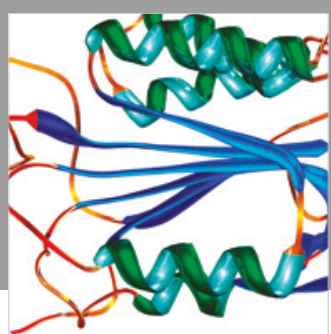

Disease Markers
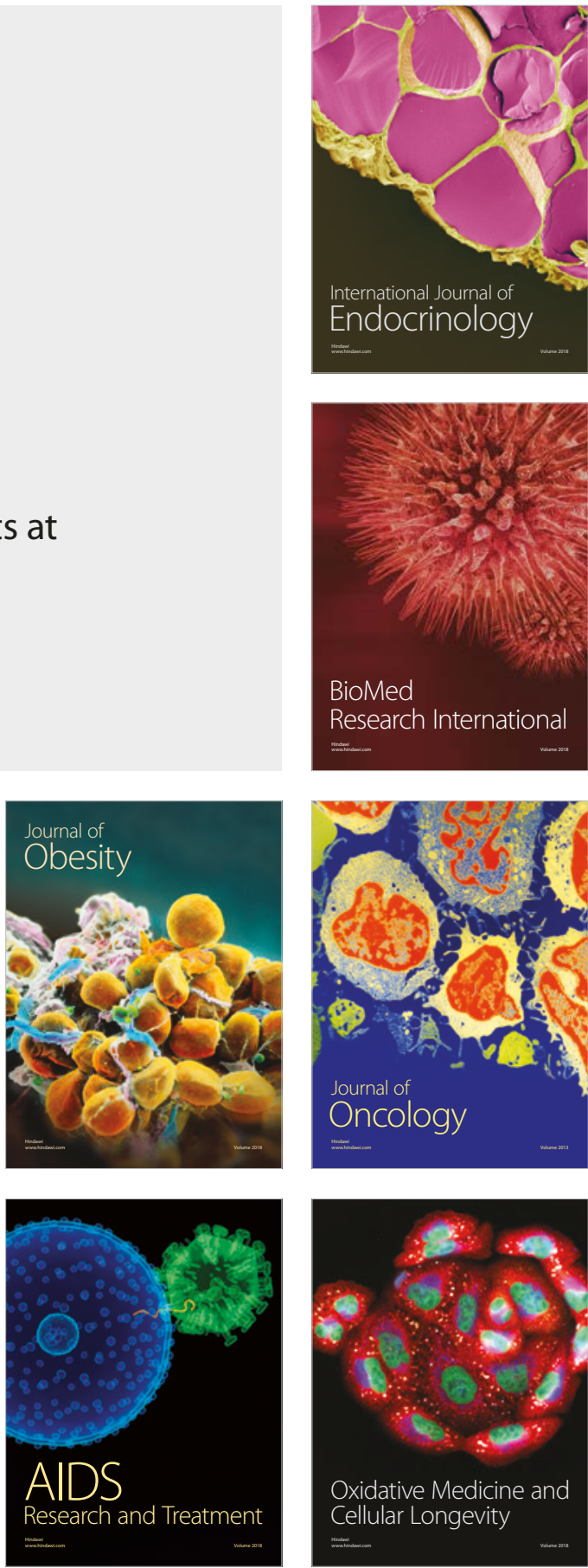